\title{
Phase and chemical equilibria in multicomponent fluid systems with a chemical reaction
}

\author{
A M Toikka, A A Samarov, M A Toikka \\ Institute of Chemistry, Saint Petersburg State University \\ Universitetskii prosp. 26, Peterhof, 198504 Saint Petersburg, Russian Federation
}

Studies of the phase and chemical equilibria in the systems with chemical reaction cover a wide range of problems related to both experimental determination of physicochemical characteristics of these systems and various aspects of thermodynamic analysis of the phase and chemical processes occurring there. The main goal of this review consists in systematization and analysis of available experimental data concerning the vapour-liquid and liquid-liquid equilibria in multicomponent systems where chemical reactions occur. The studies considered here have been mainly published in recent years, and they include rather detailed data on physicochemical properties, phase transitions and chemical processes in fluid systems, i.e., the data which are essential for thermodynamic analysis. Available approaches to the thermodynamic analysis of heterogeneous systems with chemical reactions are also discussed. Particular attention is paid to the studies of the simultaneous phase and chemical equilibria. We hope that this review could be useful both for fundamental studies of heterogeneous reactive systems and for solving applied problems on the design of combined reactive and mass-transfer processes.

The bibliography includes 79 references.

\section{Contents}

I. Introduction

II. Thermodynamic analysis of phase and chemical equilibria in multicomponent systems with chemical reaction

III. Experimental data on phase and chemical equilibria in multicomponent heterogeneous systems with chemical reactions

IV. General discussion of the data on the phase and chemical equilibria in multicomponent systems with chemical reactions

\section{Introduction}

Study of the phase equilibria in systems with chemical reactions between the components is equally significant from the standpoint of both fundamental and applied sciences. In particular, the data on simultaneous chemical

A M Toikka Doctor of Chemical Sciences, Professor, Head of the Department of Chemical Thermodynamics and Kinetics of the Institute of Chemistry of SPSU.

Telephone: +7(812)428-4052, e-mail: a.toikka@spbu.ru

Current research interests: general, chemical and non-equilibrium thermodynamics, phase and membrane processes, phase and chemical equilibria, functional materials, reactive mass-transfer processes, critical phenomena.

A A Samarov Candidate of Chemical Sciences, Postdoctoral Researcher Associate at the same Department.

Telephone: +7(812)324-1270 (ext. 5865), e-mail: samarov@yandex.ru M A Toikka Candidate of Chemical Sciences, Senior Lecturer at the same Department. Telephone: +7(812)324-1270 (ext. 5865),

e-mail: maria.toikka@chem.spbu.ru

Current research interests of the authors: chemical thermodyanmics, reactive mass-transfer processes, critical phenomena, phase and chemical equilibria, multicomponent systems, chemical engineering. equilibrium and vapour-liquid phase equilibrium are required to carry out reactive distillation processes. ${ }^{1-7}$ No less important are the details of the liquid-liquid equilibrium, for instance, to estimate whether it is possible that a reactive system would separate into phases during the chemical reaction.

The present review is devoted to analysis of the data published mainly over the past decade and concerning phase equilibria in multocomponent fluid systems with chemical reactions. Special attention is paid to the simultaneous phase and chemical equilibria. Only those studies that present comprehensive or, at least, relatively comprehensive data that are sufficient for the thermodynamic analysis are considered in detail. Inclusion in the consideration in some cases of earlier publications is additionally substantiated. In accordance with the traditional view accepted in most publications, by multicomponent systems, we mean mixtures containing no less than four compounds, in this case, provided that a chemical reaction occurs between them. The exclusion of ternary systems from the consideration is not too important as the number of experimentally studied systems is not too large. Among the few systems of this type which have been studied in detail, note the reacting system of methyl cumyl ether synthesis: the experimental results that make it possible to represent the course of the chemical equilibrium curve within the composition triangle of the methanol- $\alpha$-methylstyrene-methyl cumyl ether sys- 
tem have been reported along with the data on the simultaneous equilibrium with vapour. ${ }^{8}$

Most of the studies on phase equilibria in multicomponent reactive fluid systems deal with systems existing in the synthesis of esters of carboxylic acids. Accordingly, in this review, mixtures are systematized in terms of the starting reactants (acids). Note that the analysis of early studies (carried out before 2006) of the systems with esterification reaction (and the vapour-liquid phase equilibrium) was performed in an earlier review. ${ }^{9}$ Therefore, these early studies are not considered here as a rule, except for the cases where additional explanations are required. Apart from the systems with esterification-ester hydrolysis reactions, data on phase equilibria in the systems with transesterefication reaction are presented.

\section{Thermodynamic analysis of phase and chemical equilibria in multicomponent systems with chemical reaction}

The major approaches to the thermodynamic analysis of multicomponent reacting systems coincide with the conventional methods used to study heterogeneous systems without chemical reactions. However, it is necessary to note some specific features of state diagrams for reacting systems, which are related to the occurring chemical reactions. First of all, one should note such elements as the position of stoichiometric or reaction lines in the concentration space: their courses are determined directly by stoichiometric equation of the reaction and reflect the changes in the reaction mixture composition during the reaction. In the general case, the stoichiometric equation of a reaction in a system composed of $n$ compounds can be represented in the form

$$
\sum_{i=1}^{n} v_{i} \mathrm{R}_{i}=0
$$

where $v$ are stoichiometric coefficients, which are positive for reaction products and negative for the reactants; subscripts are compound indices; and $\mathrm{R}_{i}$ are symbols of the compounds. The change in the composition during the reaction is represented by the relation ${ }^{10}$

$$
\frac{\mathrm{d} x_{i}^{(r)}}{\mathrm{d} x_{k}^{(r)}}=\frac{v_{i}-x_{i}^{(r)} \sum_{j=1}^{n} v_{j}}{v_{k}-x_{k}^{(r)} \sum_{j=1}^{n} v_{j}}
$$

where $i, k=1,2, \ldots, n ; x_{i}$ is the mole fraction of the compound $\mathrm{R}_{i}$; the superscripts are the phase indices. Equation (2) describes changes in compound concentrations during a chemical reaction and can be considered as the equation of the reaction (stoichiometric) line.

The state of a chemical equilibrium is characterized by well-known classical conditions. ${ }^{11,12}$ In the case of one chemical reaction in the system of $n$ compounds, the chemical equilibrium condition can be expressed via the affinity (chemical affinity) of the reaction

$$
A=-\sum_{i=1}^{n} v_{i} \mu_{i}=0
$$

where $A$ is the affinity, $\mu_{i}$ is the chemical potential of the compound $i$.

In accordance with the phase rule, ${ }^{11,12}$ the number of degrees of freedom $(f)$ in a multicomponent heterogeneous system with several $(k)$ chemical reactions under the phase and chemical equilibria is determined by the following equation:

$$
f=n+2-r-k
$$

where $n$ and $r$ are the numbers of compounds and phases, respectively; $k$ is the number of reversible chemical reactions (i.e., there is $k$ chemical equilibria). Recall that, if chemical equilibria are present, the term 'number of components' usually means the difference between the numbers of compounds and reversible chemical reactions (i.e., chemical equilibria): ${ }^{12}$

$$
n-k
$$

If there is no chemical equilibrium and also if the reaction is quite slow (for instance, if it is carried out without a catalyst), the term 'component' has its usual meaning.

Note also that in this Section we restrict ourselves to thermodynamic parameters which are caloric or mechanical variables appearing in the Gibbs fundamental equation for internal energy

$$
\mathrm{d} U=T \mathrm{~d} S-P \mathrm{~d} V+\sum_{i=1}^{n} \mu_{i} \mathrm{~d} m_{i}
$$

( $U$ is internal energy; $T, S, P, V, m_{i}$ are temperature, entropy, pressure, volume and amount of substance $i$ ) or appearing in expressions for other thermodynamic potentials derived from Eqn (5) by Legendre transformations.

The application of Eqn (4) to a two-phase system with simultaneous chemical and phase equilibrium that can be shifted by changing temperature and pressure results in the following expression

$$
f=n+2-r-k=n+2-2-1=n-1
$$

Therefore, a system containing three compounds has two degrees of freedom (bivariant equilibrium), while that composed of four compounds has three degrees of freedom. Under isothermal-isobaric conditions $(T, P=$ const) and a simultaneous chemical and phase equilibrium, a two-phase system composed by four compounds exists in a monovariant equilibrium described by a curve in the composition tetrahedron in the state diagram.

In the case of a single-phase system, a curve in the composition triangle corresponds to a chemical equilibrium between three compounds under isothermal-isobaric conditions. ${ }^{10}$ If $T$ and $P$ are variable, a hypersurface in a four-dimensional space (composition $-T-P$ ) corresponds to the chemical equilibrium. If temperature (or pressure) is constant, the chemical equilibrium is described by a surface in the corresponding three-dimensional space.

In the case of interaction between four compounds, which is the most important case for the purpose of this review, a chemical equilibrium in a homogeneous system under isothermal-isobaric conditions is usually represented by a surface in the concentration tetrahedron (some examples will be given below while analyzing the data on particular systems). If temperature or pressure varies in 
such a system, a graphical representation of the chemical equilibrium is difficult since it is matched by a hypersurface in the thermodynamic space.

For systems with reactions of ester synthesis and hydrolysis

$$
\text { Alcohol }\left(\mathrm{R}_{1}\right)+\operatorname{Acid}\left(\mathrm{R}_{2}\right) \rightleftharpoons \text { Water }\left(\mathrm{R}_{3}\right)+\operatorname{Ester}\left(\mathrm{R}_{4}\right)
$$

or stoichiometrically analogous chemical reactions, the arrangement of the chemical equilibrium surfaces (at constant temperature and pressure) in the composition tetrahedron has some common features. According to the reaction equation, all of the four ternary subsystems

$$
\begin{aligned}
& \mathrm{R}_{1}-\mathrm{R}_{2}-\mathrm{R}_{3} \\
& \mathrm{R}_{1}-\mathrm{R}_{2}-\mathrm{R}_{4} \\
& \mathrm{R}_{1}-\mathrm{R}_{3}-\mathrm{R}_{4} \\
& \mathrm{R}_{2}-\mathrm{R}_{3}-\mathrm{R}_{4}
\end{aligned}
$$

are in a chemically non-equilibrium state; therefore, their compositions cannot belong to the surface of the chemical equilibrium. Obviously, two of the six binary subsystems, viz., acid-alcohol and water-ester $\left(\mathrm{R}_{1}-\mathrm{R}_{2}\right.$ and $\left.\mathrm{R}_{3}-\mathrm{R}_{4}\right)$, are not in a chemical equilibrium either. Since there is no chemical reaction in the other four binary subsystems $\left(R_{1}-R_{3}, R_{1}-R_{4}, R_{2}-R_{3}, R_{2}-R_{4}\right)$, the edges of the composition tetrahedron which correspond to these binary systems, as well as all of four vertices of the tetrahedron are the borders of the chemical equilibrium surface. At the same time, in accordance with the above, the faces and edges of the concentration tetrahedron that correspond to all of ternary and two $\left(\mathrm{R}_{1}-\mathrm{R}_{2}\right.$ and $\left.\mathrm{R}_{3}-\mathrm{R}_{4}\right)$ of binary subsystems cannot belong to this surface. Therefore, the chemical equilibrium surface for the reaction

$$
\mathrm{R}_{1}+\mathrm{R}_{2} \rightleftharpoons \mathrm{R}_{3}+\mathrm{R}_{4}
$$

is located wholly inside the composition tetrahedron and rests only upon four edges corresponding to the binary systems without chemical reactions.

The curves, surfaces and hypersurfaces of a chemical equilibrium represent a special case of isoaffine manifolds (from the word affinity) corresponding to some non-zero (the zero value corresponds to an equilibrium) but constant value of affinity in a chemical non-equilibrium state:

$$
A=-\sum_{i=1}^{n} v_{i} \mu_{i}=\mathrm{const}
$$

The manifolds of this kind are elements of the state diagrams of systems with reactions in contrast to those without reactions. These manifolds also represent curves, surfaces or hypersurfaces in the corresponding concentration space

The complexity of graphic representation of thermodynamic properties of chemical equilibrium states of multicomponent systems (and its impossibility in the case of hypersurfaces) determined the introduction of transformed composition variables (also called $\alpha$-variables) to describe chemical equilibrium compositions. The thermodynamic deduction which was first carried out by Zharov ${ }^{13}$ was based on the fact that the number of independent variables naturally decreases while the chemical equilibrium is main- tained. Indeed, in accordance with condition (4), the number of thermodynamic degrees of freedom decreases by $k$ if there are $k$ chemical equilibria. Thus, the number of composition variables can be reduced by one if one reversible chemical reaction occurs. The substantiation of the introduction of new composition variables in the original publication ${ }^{13}$ was based on analysis of fundamental thermodynamic equations. Alternative applications of $\alpha$-variables to the thermodynamic analysis of reacting systems of different kinds were considered later in many studies, and, first of all, in the studies performed at the Lomonosov Moscow University of Fine Chemical Technology and Saint Petersburg State University (see, for example, Refs 14-19).

Much later, virtually the same transformed composition variables were suggested by Barbosa and Doherty ${ }^{20}$ on the basis of material balance equations. The composition variables in the Janecke indices, which are particularly applied for constructing the diagrams of systems with an exchange reaction are also worth to be mentioned.

Consider a special case, which is especially important for this review, viz., a system of four compounds $(n=4)$ with esterification reaction of the type

$$
\sum_{i=1}^{n} v_{i} \mathrm{R}_{i}=\sum_{i=1}^{4} v_{i} \mathrm{R}_{i}=-\mathrm{R}_{1}-\mathrm{R}_{2}+\mathrm{R}_{3}+\mathrm{R}_{4}=0
$$

$\left(v_{1}=-1, v_{2}=-1, v_{3}=1, v_{4}=1\right)$. In this case, the transformed composition variables ( $\alpha$-variables) have the following forms

$$
\begin{aligned}
& \alpha_{1}=x_{1}+x_{4} \\
& \alpha_{2}=x_{2}+x_{4} \\
& \alpha_{3}=x_{3}-x_{4}
\end{aligned}
$$

Obviously, the following conditions are also met:

$$
\begin{gathered}
\alpha_{1}+\alpha_{2}+\alpha_{3}=1 \\
0<\alpha_{1}<1 \\
0<\alpha_{2}<1 \\
-1<\alpha_{3}<1
\end{gathered}
$$

Thus, the concentration space can be represented by a square of $\alpha$-variables, i.e., by a two-dimensional composition complex, instead of three-dimensional concentration simplex (a composition tetrahedron). Examples of application of transformed composition variables will be given in the next section while discussing particular systems.

In addition to the particular location of manifolds of chemical equilibria and stoichiometric lines, analysis of reactive systems can consider the regularities of changes in the thermodynamic properties on these manifolds and lines, as well as the mutual arrangement of the surfaces of phase and chemical equilibria. We will briefly discuss these issues, mainly giving references to the relevant original papers. The following problems are of practical interest in the first place:

- the conditions for a pressure or temperature extremum on stoichiometric (reaction) lines;

- the conditions for a pressure or temperature extremum on the manifolds of a chemical equilibrium and the criterion of composition invariance for reacting liquid mixture in the course of a non-equilibrium chemical reac- 
tion in a vapour-liquid system (chemical azeotrope, reactive azeotrope, kinetic azeotrope);

- analysis of the mutual arrangement of manifolds of chemical and phase equilibria if they cross in the concentration space.

The conditions of pressure extremum on the reaction lines were considered ${ }^{21}$ on the basis of the generalized Storonkin - van der Waals differential equation. According to the results of this study, a pressure extremum on the reaction line in a system of four compounds with a chemical reaction may be associated with three different reasons: (i) the tie-line is orthogonal to chemical affinity gradient and, hence, it belong to a surface tangent to the isoaffine surface; (ii) the tie-line is of zero length, i.e., there is an azeotropic point; (iii) a specific point of the vector field in which $\operatorname{grad} \mathrm{A}$ is a zero vector corresponds to the pressure extremum.

For better illustration, we turn to a reactive system of three substances. ${ }^{22}$ The conditions of existence of a stationary point on the pressure dependence on composition along the reaction lines is reduced to simpler statements in this case: (i) the chemical affinity isoline and the vapourliquid tie-line are tangent to each other; (ii) the compositions of the liquid and vapour phases are equal (a usual azeotrope point); (iii) the derivatives of affinity with respect to concentration are equal to zero. Clearly, the first of these conditions is most interesting as it is nontrivial; it is illustrated in Fig. 1. Other conditions represent two special conditions of a stationary point.

The conditions for pressure or temperature extremum in the chemical equilibrium manifolds, as well as the conditions of composition invariability in a reacting liquid mixture during a non-equilibrium chemical reaction in a vapour-liquid system have been repeatedly discussed in the literature. In the general case, the conditions of invariability of composition of a reaction mixture with simple vaporization are related to the relative arrangement of the reaction lines and directions of the vapour-liquid tie-lines (i.e., the direction of simple vaporization). Obviously, if the rates of vaporization and the chemical reaction are equal but opposite in direction (in the concentration space), the composition of the reaction mixture is constant (i.e., there is a stationary point). The special points of this type (chemical

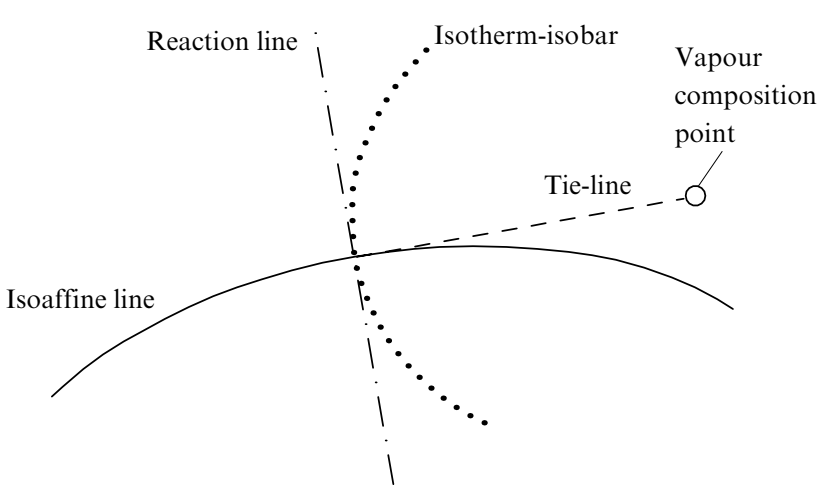

Figure 1. Relative arrangement of the chemical affinity isoline (the isoaffine line), the vapour-liquid tie-line, the reaction line and the isotherm-isobar at the pressure extremum point in the reaction line in a system of three compounds (the first case). ${ }^{22}$ azeotrope or reactive azeotrope) are of interest to design combined reactive mass-transfer processes in chemical engineering. Conditions for shifting or invariability of the composition are also considered both for preserved chemical equilibrium and for a non-equilibrium state (in the latter case, the term 'kinetic azeotrope' is used). Nonetheless, experimental data concerning the singular points of this type are rather scanty (particular examples are given in the next section). Therefore, here we just give references to some recent publications (theoretical publications, first of all) in this field. ${ }^{23-25}$

Analysis of intersections of the manifolds of phase and chemical equilibria in the concentration space is of practical interest for considering immiscible solutions. Such an intersection of the thermodynamic surfaces means that there is a chemical equilibrium in both homogeneous and heterogeneous regions of the reaction mixture compositions. A simple illustration can be done for a ternary system: an intersection of a binodal and the chemical equilibrium line are considered in this case.

One of the possible forms of diagram for such a system is shown in Fig. 2 as a vivid example. In this case, during the reaction

$$
\sum_{i=1}^{3} v_{i} \mathbf{R}_{i}=v_{1} \mathrm{R}_{1}+v_{2} \mathrm{R}_{2}+v_{3} \mathrm{R}_{3}=0
$$

where $v_{3}$ has the sign opposite to the signs of $v_{1}$ and $v_{2}$, or, alternalevely,

$$
\left|v_{1}\right| \mathbf{R}_{1}+\left|v_{2}\right| \mathbf{R}_{2}=\left|v_{3}\right| \mathbf{R}_{3}
$$

the chemical equilibrium for some compositions of the reaction mixture is reached in the phase separation region, i.e., in a two-phase heterogeneous region.

The true compositions of phases of the chemically equilibrium heterogeneous system correspond to the points $\mathrm{L}_{1}$ and $\mathrm{L}_{2}$ of the binodal in Fig. 2, and the overall compositions of the chemically equilibrium mixtures belong to the $\mathrm{L}_{1}-\mathrm{L}_{2}$ line. Lines of this type were called unique reactive liquid-liquid tie-lines. ${ }^{26}$ Later, a particular ternary system (cyclohexene + water $\rightarrow$ cyclohexyl alcohol) in which

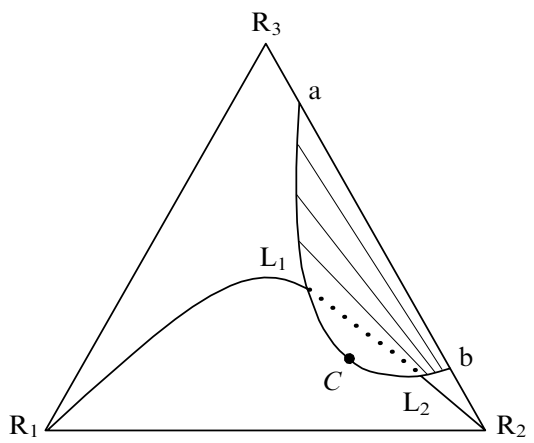

Figure 2. Schematic diagram of a system with the chemical reaction $\left|v_{1}\right| \mathbf{R}_{1}+\left|v_{2}\right| \mathbf{R}_{2}=\left|v_{3}\right| \mathbf{R}_{3}$ and a chemical equilibrium in both homogeneous and heterogeneous composition regions.

$\mathrm{a}, \mathrm{b}$ is binodal; $\mathrm{R}_{1}-\mathrm{R}_{2}$ is the chemical equilibrium curve; straight lines are the liquid-liquid tie-lines; $C$ is a critical point of the liquid - liquid equilibrium; dotted line $\mathrm{L}_{1}-\mathrm{L}_{2}$ is a singular (unique) reaction tie-line. 
a chemical equilibrium is established both in homogeneous and heterogeneous regions was considered using model calculations. ${ }^{27}$

As for the systems of four compounds, a diagram of simple vaporization including homogeneous and heterogeneous regions of the chemical equilibrium for n-propyl laurate synthesis was reported. ${ }^{28}$ Note that, strictly spealing, a shift in a solution composition in the chemical equilibrium surface should be considered as a result of combined reactive mass-transfer processes including the reaction and vaporization. The relative arrangement of bimodal surfaces and chemical equilibrium surfaces was studied more thoroughly for the systems formed in the syntheses of ethyl acetate and n-propyl acetate: an intersection of these surfaces is observed in the latter case. Specific features of these systems are discussed in the next section where experimental data are analyzed.

In addition to the problems listed above, of certain interest is also analysis of the changes in affinities in the reactive systems depending on the arrangement of tie-lines and binodals. Some results concerning this problem were obtained in several studies. ${ }^{29,} 30$ It should also be noted that for process design in chemical industry, thermodynamic topological analysis is of significant importance since its results are highly valuable for the development of flow charts for combined reactive mass-transfer processes. ${ }^{31-35}$

\section{Experimental data on phase and chemical equilibria in multicomponent heterogeneous systems with chemical reactions}

Here, the key attention is paid to the studies published after 2005 and also to some earlier studies (published mainly after 2001) which were not discussed in the previous review devoted to the systems with the esterification reaction and the liquid-vapour phase equilibrium. Exceptions are several publications also not considered in earlier review ${ }^{9}$ which are mainly devoted to chemical equilibria (but not to a vapour-liqiud phase equilibrium) and included because a comprehensive review should cover the whole body of detailed and reliable data even though they were obtained rather long ago. It should also be noted that the cited studies not necessarily include simultaneous investigation of both phase and chemical equilibria. However, the set of data even if they were obtained by different authors who studied one or other equilibrium is undoubtedly useful for thorough characterization of a heterogeneous reactive system if, of course, the data are correct. Note also that some authors presented their data on phase and chemical equilibria in different publications (see, for instance, the systems with reactions of synthesis of ethyl acetate and n-propyl acetate).

\section{III.1. Systems with the esterification reaction}

Table 1 summarizes the principal sources of data on the phase and chemical equilibria in the systems with reactions of esterification and hydrolysis of esters (note that the review ${ }^{9}$ rather than original studies is indicated in many cases).

III.1.a. Formic acid-methanol-methyl formate-water Apparently, this system was the first multicomponent system with chemical reactions for which complete and
Table 1. Sources of thermodynamic data for the systems with the reactions of esterification-hydrolysis.

\begin{tabular}{ll}
\hline Ester & Ref. \\
\hline Methyl formate & $9,36-38$ \\
Ethyl formate & 37,38 \\
n-Propyl formate & 38 \\
Isopropyl formate & 37,38 \\
Methyl acetate & $9,39,40$ \\
Ethyl acetate & $9,41-46$ \\
n-Propyl acetate & $9,29,47-52$ \\
Isopropyl acetate & 9 \\
n-Butyl acetate & $9,53-56$ \\
n-Pentyl acetate & 9,57 \\
Isopentyl acetate & 9 \\
n-Hexyl acetate & 9,58 \\
n-Propyl propionate & 59 \\
n-Butyl propionate & 9 \\
Isopentyl propionate & 60 \\
Methyl laurate & 9 \\
2-Ethylhexyl laurate & 9 \\
n-Propyl laurate & 9 \\
Methyl oleate & 9,61 \\
Methyl lactate & 62 \\
Ethyl lactate & 63 \\
\hline &
\end{tabular}

detailed experimental results indicating simultaneous chemical and phase equilibria were obtained. ${ }^{15}$

$\mathrm{HCO}_{2} \mathrm{H}+\mathrm{MeOH} \rightleftharpoons \mathrm{HCO}_{2} \mathrm{Me}+\mathrm{H}_{2} \mathrm{O}$

The chemical equilibrium surface in the irregular concentration tetrahedron obtained on the basis of these data and a short discussion of the results are given in the cited review. ${ }^{9}$ A new, more vivid form of the three-dimensional diagram in the composition tetrahedron is shown in Fig. 3: the experimentally determined ${ }^{15}$ points of compositions of mixtures at chemical equilibrium for which the vapour-

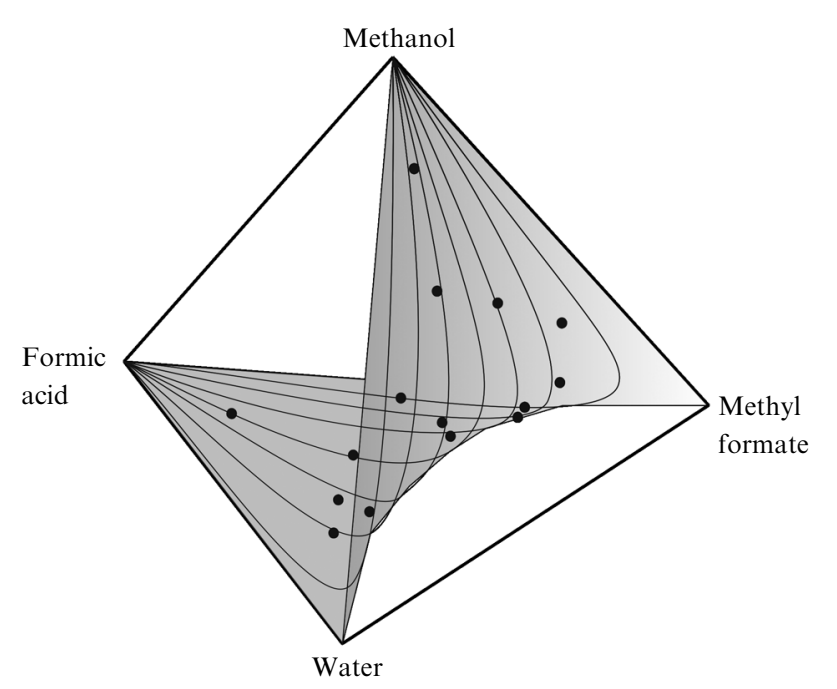

Figure 3. The chemical equilibrium surface in the formic acidmethanol-methyl formate - water system.

Dark points are the composition points corresponding to the chemical equilibrium compositions. 
liquid equilibrium was also studied are indicated in the chemical equilibrium surface.

In addition, in this study, ${ }^{15}$ transformed composition variables $(\alpha$-variables) were used for the first time to express thermodynamic properties of the chemically equilibrium states. Subsequently, there was no detailed investigation of the simultaneous phase and chemical equilibria in this system, although data on the chemical equilibrium were published. ${ }^{36}$ Unfortunately, these data were not completely correct as one can see from their presentation in the original text; in particular, a shift of the chemical equilibrium under the action of a catalyst was reported there, although, obviously, it was actually a change in the rate and completeness of chemical equilibrium.

It is also necessary to point out a publication of Tischmeyer and Arlt, ${ }^{37}$ who studied the dependences of temperature, pressure and composition during chemical reaction (viz., during methyl formate synthesis), i.e., along the reaction (stoichiometric) lines. The measurement of phase equilibria parameters in this quaternary system was not the aim of this research. The aim was to use these data for estimating the characteristics of several binary systems containing aliphatic alcohol and carboxylic acid, including the methanol-formic acid system. The reason of the use of this approach consisted in difficulty of direct and accurate measurement of parameters of the vapour-liquid equilibrium if components react giving, in the case of esterification, two additional components (methyl formate and water). The approach providing quite accurate data was based on determining the phase equilibrium shift depending on the composition of the liquid phase (liquid phases) during the chemical reaction. This method including both experimental measurements and modelling seems quite reasonable. Some data on the concentration of the components in the vapour phase were obtained in these experiments; however, the approaches based on modelling (Wilson equation, other models of local compositions, the UNIFAC model ${ }^{\dagger}$ ) prevailed in this study, in particular, in the determination of vapour compositions. The experimentally obtained data on the concentration in the vapour were only used for additional verification of the results of model calculations. The possibility of phase separation during esterification was also shortly discussed. The data in this study ${ }^{37}$ were obtained in the $313-333 \mathrm{~K}$ temperature range; the chemical equilibrium was not investigated there.

Noteworthy is also the paper of Pisarenko and Balashov, ${ }^{64}$ who report the results of the chemical equilibrium calculations, as well as earlier study ${ }^{38}$ reporting experimental data on the chemical equilibrium at $373 \mathrm{~K}$.

\section{III.1.b. Formic acid-ethanol-ethyl formate-water}

The data on the vapour-liquid equilibrium in the temperature range of $313-333 \mathrm{~K}$ in the system with the reaction of ethyl formate synthesis were reported in the paper of Tischmeyer and Arlt. ${ }^{37}$

$$
\mathrm{HCO}_{2} \mathrm{H}+\mathrm{EtOH} \rightleftharpoons \mathrm{HCO}_{2} \mathrm{Et}+\mathrm{H}_{2} \mathrm{O}
$$

$\dagger$ UNIFAC (UNIQUAC Functional-group Activity Coefficients) is a model to describe thermodynamic characteristics based on parameters of the functional groups of compounds.
The temperature, pressure and composition dependences during esterification in the starting binary system of formic acid and ethanol (along the reaction lines), and also phase separation in the reaction mixture during the reaction were studied. As in the case of the above discussed system with the reaction of formation of methyl formate, the aim of this study was, first of all, to estimate characteristics of the binary system composed of the aliphatic alcohol and the carboxylic acid but not to find phase equilibria parameters for the ethyl formate-ethanol-formic acid-water quaternary system. The data on thermodynamic properties of the quaternary system were necessary for more accurate determination of the parameters of the vapour-liquid equilibrium in the starting binary system with a chemical reaction of components. Thus, the authors were able to correlate the phase equilibrium shift with a possible change in the solution composition caused by the chemical reaction. It is worth noting that despite the obtained direct experimental data on the vapour composition of the quaternary mixtures, the authors predominantly used modelling for estimation of compositions, while the experimental data about the vapour phase served to check the modelling reliability. The chemical equilibrium was not investigated there. As a source of experimental data on the chemical equilibrium at $373 \mathrm{~K}$, an earlier publication ${ }^{38}$ can be indicated.

III.1.c. Formic acid-n-propyl alcohol-n-propyl formate-water To the best of our knowledge, there is no recent experimental study of chemical or phase equilibrium in this system.

$$
\mathrm{HCO}_{2} \mathrm{H}+\mathrm{Pr}^{\mathrm{n}} \mathrm{OH} \rightleftharpoons \mathrm{HCO}_{2} \mathrm{Pr}^{\mathrm{n}}+\mathrm{H}_{2} \mathrm{O}
$$

Therefore, we refer only to the publication ${ }^{38}$ considering the chemical equilibrium at $373 \mathrm{~K}$ in which 19 chemical equilibrium compositions were identified (the paper contains references to even earlier studies). The analysis of the data on the chemical equilibrium included determination of equilibrium constants expressed in concentration units. The obtained data were also used to calculate heats of formation of the compounds involved.

III.1.d. Formic acid-isopropyl alcohol-isopropyl formate-water The data on the vapour-liquid equilibrium in this system in the $313-353 \mathrm{~K}$ temperature range were reported in a study of Tischmeyer and Arlt, ${ }^{37}$ which was cited above.

$$
\mathrm{HCO}_{2} \mathrm{H}+\mathrm{Pr}^{\mathrm{i} O H} \rightleftharpoons \mathrm{HCO}_{2} \mathrm{Pr}^{\mathrm{i}}+\mathrm{H}_{2} \mathrm{O}
$$

Dependences of temperature, pressure and composition during esterification of formic acid with isopropyl alcohol along the stoichiometric lines in the concentration space of the quaternary system were given. As in the cases of the systems considered above (the methyl and ethyl formate syntheses), one of the main goals of this study was to establish the precise parameters of the vapour-liquid equilibrium in the aliphatic alcohol-carboxylic acid binary system, while ascertainment of parameters of the phase equilibria in the formic acid-isopropyl alcohol-isopropyl formate - water quaternary system was an additional, auxiliary purpose of the research. The data on the phase equilibrium in the quaternary system made it possible to take into account the possible shift of the phase equilibrium due to variation in the composition of the acid-alcohol binary system during the reaction. The obtained experimen- 
tal data were used for verification of the model calculations of the phase equilibrium in the quaternary system carried out by the authors. The chemical equilibrium was not explored, a possible source of experimental data on this system can be an earlier publication of Schultz. ${ }^{38}$

\section{III.1.e. Acetic acid - methanol-methyl acetate-water}

Note that most complete and reliable data concerning the vapour-liquid equilibrium for chemical equilibrium conditions in this system were obtained in the study of Bernatová et al., ${ }^{19}$ which has already been discussed in the review. ${ }^{9}$

$$
\mathrm{MeCO}_{2} \mathrm{H}+\mathrm{MeOH} \rightleftharpoons \mathrm{MeCO}_{2} \mathrm{Me}+\mathrm{H}_{2} \mathrm{O}
$$

Some additional results obtained in subsequent studies concern the liquid-liquid equilibria and problems of reactive distillation. In particular, experimental data on the liquid-liquid equilibrium were obtained ${ }^{39}$ for the acetic acid-methanol-methyl acetate-water quaternary system and the acetic acid - methyl acetate - water ternary system at 293, 303, 313 and $323 \mathrm{~K}$ and under atmospheric pressure. The NRTL $\$$ and UNIQUAC; $\$$ models were applied for correlation of the experimental data and for calculation of activity coefficients. A good agreement between the experimental data and modelling results was noted.

The study of Zuo et al. ${ }^{40}$ was mainly devoted to problems (kinetics and catalysis) of the synthesis of methyl acetate and to the design of the reactive distillation process. At the same time, the chemical equilibrium constant ( $K_{\text {eq }}$, expressed through the component activities), which was derived from authors' experimental data, and its temperature dependence in the $318.15-333.15 \mathrm{~K}$ range were also reported:

$$
\ln K_{\text {eq }}=\frac{2565.1}{T}-4.7335
$$

Among other recent studies, it is worthy to mention the study of Navarro-Espinosa et al., ${ }^{65}$ who considered a series of binary systems, being subsystems of quaternary systems with esterification in progress at a pressure of $77.3 \mathrm{kPa}$. The authors indicated that the circulation apparatus was used in the experiments to study the vapour-liquid equilibrium in the systems with a chemical reaction. At the same time, it is not entirely clear how the possible occurrence of the esterification reaction was checked when the methanolacetic acid system was studied or, in other words, if the data on the equilibrium are really the data for the binary system but not for a reaction mixture containing at least traces of methyl acetate. Possibly, the authors thought that this reaction was inhibited under the conditions they used (reduced pressure and no catalyst). Note that in an earlier study of other authors, ${ }^{66}$ it was noted that the reaction between an acid and an alcohol is slow at 298.15 and $323.15 \mathrm{~K}$ and, hence, it is difficul to detect the vapour-

+ NRTL (Non-Random Two Liquid model) is a model describing excessive Gibbs energy of a homogeneous or phase-separated solutions; this makes it possible, in particular, to determine the activity coefficients. $\S$ UNIQUAC (UNIversal QUasi-Chemical) is a known model for calculation of excessive Gibbs energy and other thermodynamic characteristics on the basis of the universal quasi-chemical theory. liquid equilibrium in this binary system. Nevertheless, some data concerning the equilibrium with vapour in the methanol-acetic acid system were obtained by shortening the time of experiments and presented in that paper. ${ }^{66}$

\section{III.1.f. Acetic acid-ethanol-ethyl acetate - water}

Bernatová et al. ${ }^{41}$ obtained experimental data on the combined phase and chemical equilibrium for the acetic acidethanol-ethyl acetate-water system; 39 compositions corresponding to the chemical equilibrium at $348.15 \mathrm{~K}$ were investigated.

$$
\mathrm{MeCO}_{2} \mathrm{H}+\mathrm{EtOH} \rightleftharpoons \mathrm{MeCO}_{2} \mathrm{Et}+\mathrm{H}_{2} \mathrm{O}
$$

The data were analyzed using the NRTL model. The binary parameters of the model of four binary systems without a chemical interaction were obtained by processing the available data taking into account that the vapour phase was non-ideal. The parameters of the NRTL model for two systems with chemical reactions (ethyl acetate-water and acetic acid - ethanol) were estimated during optimization of the data for the quaternary system. The correlation results indicate a good agreement between the theoretical and experimental data. Transformed composition variables were used in the graphic representation of the data with reference to a work of Barbosa and Doherty. ${ }^{20}$ The authors also presented three-dimensional images of the surfaces of equilibrium liquid and vapour phases for the chemical equilibrium states above the square of transformed composition variables. The esterification was carried out in the presence of a catalyst ( 1.5 mass $\%$ of $p$-toluenesulfonic acid); the authors pointed to the reliability of their data on the chemical equilibrium. On the whole, the study cited ${ }^{41}$ is one of the most thorough and detailed studies dealing with the simultaneous phase and chemical equilibria and is characterized by clear statements and presentation of the results.

In contrast to this study, ${ }^{41}$ the work of $\mathrm{Hu}$ et al. ${ }^{67}$ is mainly devoted to applied aspects such as intensification of the reactive distillation with participation of n-butyl acetate as a separating agent, which, according to authors' estimates, results in substantial decrease in power consumption for ethyl acetate synthesis (by up to $32 \%$ ). The results of this study are largely based on analysis of the phase equilibria in the acetic acid-ethanol-ethyl acetate-water system, thus illustrating the practical importance of data on the phase equilibrium in reacting systems. The NRTL model parameters recommended for simulation of the process are reported in this paper.

The purpose of the study of Modla ${ }^{42}$ was also the design of reactive distillation. Nevertheless, diagrams of simple vaporization in ternary and quaternary systems were given in this paper along with rather detailed discussion. The system behaviours were considered either in the presence of a chemical reaction (in the chemical equilibrium state) or without the reaction (in absence of a catalyst). In the latter case, the simple vaporization curves can be represented for all of the four ternary systems; diagrams for pressures of 101 and $1000 \mathrm{kPa}$ were presented. The simple vaporization curves in the quaternary system are shown in the concentration tetrahedron for the same pressures. The lines of composition changes presented in the squares of transformed composition variables ${ }^{20}$ for the same pressures of 101 and $1000 \mathrm{kPa}$ are located on the surface of the chemical 
equilibrium and, therefore, they are the curves of a combined reactive mass transfer process, which includes vaporization and the reaction. It was also indicated that a reactive azeotrope exists for this system (on the surface of the chemical equilibrium), the composition of this azeotrope significantly depends on pressure.

The work of Zheng et al. ${ }^{43}$ was devoted to analysis of the simple vaporization curves in the acetic acid-ethanolethyl acetate-water system. The NRTL model was used in the calculations. The authors considered transformations of diagrams of the combined reactive mass transfer process (reaction + vaporization) while varying the Damköhler numbers, which characterize the relative rates of the reaction and vaporization. Particularly, the zero value of a Damköhler number means that there is no reaction in the system. The simulated diagram of curves (of simple vaporization, in this case) in the concentration tetrahedron was presented. Simultaneously, the authors presented a diagram in a rectangle ('for a better visualization'); however, its meaning is not completely clear: this diagram cannot be a square of transformed composition variables since not only the chemical equilibrium surface was considered but the whole range of states of this system. The given reference to a thesis performed at the National Taiwan University of Science and Technology is not sufficient because of inaccessibility of this source. Another diagram in this publication ${ }^{43}$ illustrates the transformation of curves of the combined process for different Damköhler numbers. The authors also presented their own scheme of the ethyl acetate synthesis, which was based on the analysis of curves of the combined process.

The set of two publications ${ }^{44,45}$ present a study of both the chemical equilibrium and the liquid-liquid equilibrium. The position of the binodal surface was additionally determined by the cloud-point technique (isothermal titration for clouding and clearing of the solution). The reaction was conducted in the presence of an acid catalyst, the compositions of chemical equilibrium mixtures and equilibrium liquid phases were determined by gas chromatography in both studies. The experimental data on the liquid-liquid equilibrium were compared with the results of calculations using the UNIFAC model, a good agreement between the experimental and calculated data was observed. As a result of the investigation of the chemical equilibrium during the esterification reaction, 64 chemical equilibrium compositions were found, which made it possible to represent the position of the chemical equilibrium surface in the composition tetrahedron fairly accurately. As a result of the study of the phase equilibrium, location of 19 liquid-liquid tie-lines was established in the quaternary system, 8 tie-lines were found in the acetic acid-ethyl acetate-water subsystem and 6 tielines were detected in the ethanol-ethyl acetate-water subsystem. Determination of the position of the solubility surface by the isothermal titration method resulted in identification of 52 solution compositions on this surface. Thus, the results provide quite accurate representation of the binodal surface and location of the liquid-liquid tielines in the acetic acid-ethanol-ethyl acetate-water system. In addition, the compositions of 5 solutions corresponding to the liquid-liquid critical state were determined, ${ }^{45}$ which made it possible to construct the critical curve in the concentration tetrahedron. The data obtained also gave a possibility to estimate the relative arrangement of the surfaces of the chemical and phase (liquid-liquid) equilibria in the concentration space.

Concluding the discussion of the system with the reaction of formation of ethyl acetate, it should be noted that the ethanol-acetic acid system was also studied at a pressure of $77.3 \mathrm{kPa}$ in the work of Navarro-Espinosa et al. ${ }^{65}$ mentioned above while discussing the reaction of methyl acetate synthesis. As in the case of the acetic acidmethanol system, in the case of the binary system under discussion with possible occurrence of esterification, the authors assumed apparently that the reaction was inhibited under the conditions used (low pressure and no catalyst). Accordingly, the presence of the reaction products (ethyl acetate and water) was ruled out during the investigation of the vapour-liquid equilibrium. It is worth noting that the results of a study of the vapour-liquid equilibrium in this binary system at $298.15 \mathrm{~K}$ were also reported ${ }^{68}$ without mentioning the possibility of a chemical reaction between ethanol and acetic acid; this is in agreement, to some extent, with the above assumption that this reaction could be ignored in the performed experiments.

It is also necessary to mention the mainly theoretical study ${ }^{46}$ dealing with modelling of a combined chemical and phase equilibrium in the course of the esterification reaction in carbon dioxide at high pressures.

\section{III.1.g. Acetic acid-n-propyl alcohol-n-propyl acetate-water}

A short survey of the data published earlier and devoted to the vapour-liquid, liquid-liquid equilibria and the chemical equilibrium in the acetic acid-n-propyl alcoholn-propyl acetate - water system has been reported. ${ }^{47}$

$$
\mathrm{MeCO}_{2} \mathrm{H}+\mathrm{Pr}^{\mathrm{n}} \mathrm{OH} \rightleftharpoons \mathrm{MeCO}_{2} \mathrm{Pr}^{\mathrm{n}}+\mathrm{H}_{2} \mathrm{O}
$$

Also, data of different authors concerning characteristics of azeotropes in this system at $313.15 \mathrm{~K}$ were considered. Some graphical illustrations were presented, including the chemical equilibrium surface in the composition tetrahedron, the vapour-liquid isotherms-isobars on the chemical equilibrium surface projected onto the square of $\alpha$-variables, including those with marked pressure maximum points on these surfaces. The qualitative pattern of the evaporation curves under chemical equilibrium being maintained (a combined reactive mass-transfer process: reaction + vaporization) was presented and a brief analysis of the system phase diagram was given. In addition, the shape of the binodal surface was shown in illustrations of the paper. The main objective of this work ${ }^{47}$ comprised also analysis of available contradictory data concerning the phase behaviour of the system under consideration. In particular, the possibility of intersection of the surfaces of the chemical and phase equilibria in the concentration space was discussed; however, the final conclusion remained open to question because of deficiency of the experimental data.

Experimental data on the solubility and compositions of the critical points in the acetic acid-n-propyl alcoholn-propyl acetate-water system at $313.15 \mathrm{~K}$ were obtained in the study of Toikka et al. ${ }^{48}$ In addition to detailed information about the position of the solubility surface in the quaternary system, it was proven on the basis of the performed study that there is a composition region simultaneously belonging to both the chemical equilibrium surface and the solubility surface, i.e., an intersection of these surfaces in the concentration space (tetrahedron) was ascer- 
tained. It was also shown for the first time that there are liquid-liquid critical points that simultaneously belong to chemical equilibrium. The solubility diagrams were presented for a series of cross-sections of the concentration tetrahedron, as well as the whole solubility surface and the location of the phase separation region on the surface of chemical equilibrium in the square of $\alpha$-variables.

A paper ${ }^{49}$ devoted to the general characteristics of solubility in the systems with chemical reactions considers, as an example, the system with the reaction of n-propyl acetate synthesis. Special attention was paid to the critical states of the liquid-liquid systems in chemically active media. The topology of the liquid-liquid equilibrium diagrams was discussed. In particular, as an illustration, the region of intersection of the surfaces of the chemical and phase equilibria for the acetic acid-n-propyl alcoholn-propyl acetate - water system in the concentration tetrahedron was presented with indication of the pattern of the critical curve and location of chemical equilibrium critical points at $313.15 \mathrm{~K}$. The diagram in $\alpha$-variables, which illustrated the location of the chemical equilibrium critical points and the phase separation region on the chemical equilibrium surface, was also given.

New experimental data on the solubility and the liquid-liquid equilibrium in the n-propyl alcohol-n-propyl acetate-water ternary subsystem at 293.15, 303.15 and $313.15 \mathrm{~K}$ were reported by Toikka et al. ${ }^{50}$ The results of calculations of the liquid-liquid equilibrium with the use of the UNIFAC model were presented. They are in a good agreement (from practical point of view) with experimental data.

The purpose of the study of Toikka et al. ${ }^{51}$ comprised experimental identification of the chemical equilibrium states in the acetic acid-n-propanol-n-propyl acetatewater system at $303.15 \mathrm{~K}$ and calculations of the vapourliquid equilibrium in the framework of the UNIFAC model. Preliminarily, calculations of the vapour-liquid equilibrium at $313.15 \mathrm{~K}$ were performed using this model because there were literature data concerning the phase and chemical equilibrium at this temperature and this provided the possibility to assess precision of the calculations and make a conclusion about applicability of the UNIFAC model for $303.15 \mathrm{~K}$. The results obtained were used to construct the isotherms-isobars of the liquid phase, which were presented as projections onto square of $\alpha$-variables with indication of the phase separation region for the solution under the chemical equilibrium.

III.1.h. Acetic acid-n-butanol-n-butyl acetate-water This system belongs to the most studied systems.

$\mathrm{MeCO}_{2} \mathrm{H}+\mathrm{Bu}^{\mathrm{n}} \mathrm{OH} \rightleftharpoons \mathrm{MeCO}_{2} \mathrm{Bu}^{\mathrm{n}}+\mathrm{H}_{2} \mathrm{O}$

A brief description of numerous earlier studies is given in the review cited above. ${ }^{9}$ In addition, it is necessary to mention another early study ${ }^{53}$ where solubility and the liquid-liquid equilibrium at $298 \mathrm{~K}$ under atmospheric pressure were investigated in detail and with quite high precision (up to 1 mass \%).

The most interesting recent study was carried out by Grob and Hasse. ${ }^{54}$ The phase and chemical equilibria were studied predominantly for temperatures at which industrial processes are usually carried out $(353.15-393.15 \mathrm{~K})$, i.e., at temperatures close to boiling points. The vapour-liquid equilibrium was ascertained for binary and ternary subsys- tems, several results were also reported for the quaternary system. The chemical equilibrium was investigated at $353.15,373.15$ and $393.15 \mathrm{~K}$. One of the advantages of this work lies in the fact that the liquid-liquid equilibrium was explored both for the homogeneous region of compositions of the reaction mixture under chemical equilibrium and for the phase separation region. Thus, it can be concluded that the binodal and chemical equilibrium surfaces do intersect in the concentration space at these temperatures (unfortunately, no graphical illustration is given in the paper). To correlate the obtained experimental data, the authors used different models such as NRTL, UNIQUAC, COSMO-RS and the PC-SAFT equation of state. ${ }^{\top}$ The results of calculations obtained with the use of all models are in good agreement with experimental data; however, the best results (from the point of view of best capability in prediction of properties of this system) were obtained using COSMO-RS. The presented graphical illustrations also include diagrams in transformed composition variables for the chemical equilibrium states.

An experimental study of the chemical equilibrium in the acetic acid-n-butanol-n-butyl acetate-water system was also carried out at the temperature of $358 \mathrm{~K},{ }^{55}$ which corresponds to the conditions of implementation of the combined reactive mass transfer process. Compositions of 18 solutions corresponding to the chemical equilibrium were found. The mathematical treatment of the results to obtain the equilibrium constant was described in detail in this publication; the recommended value of the constant is 18.0 .

The vapour-liquid equilibria in the acetic acid-n-butyl acetate, n-butanol-n-butyl acetate, n-butanol-water binary systems at $101.3 \mathrm{kPa}$ and the liquid-liquid equilibrium in the n-butanol-water binary system were studied by Lladosa et al. ${ }^{56}$ Despite the fact that some chemical equilibrium data were not reported, it follows from the text that the vapour-liquid equilibrium in the quaternary system was determined for the chemical equilibrium states. The chemical equilibrium compositions are directly presented in the table of data on the vapour-liquid equilibrium. This reaction was carried out in the presence of a catalyst ( $p$-toluenesulfonic acid) in the amount (according to the published data) of 1.5 mass $\%$. Therefore, as follows from the text, ${ }^{56}$ the vapour-liquid equilibrium corresponds to the phases additionally containing also this acid. While studying the vapour-liquid equilibrium, the compositions were analyzed by gas chromatography; the liquid-liquid equilibrium in the binary system was determined visually during titration as the solution cloud point. The data were correlated using the NRTL and UNIQUAC models.

\section{III.1.i. Acetic acid-n-pentanol-n-pentyl acetate-water}

The simultaneous phase and chemical equilibrium in the acetic acid-n-pentanol-n-pentyl acetate-water system was studied by a static method. ${ }^{57}$

$$
\mathrm{MeCO}_{2} \mathrm{H}+\mathrm{n}-\mathrm{C}_{5} \mathrm{H}_{11} \mathrm{OH} \rightleftharpoons \mathrm{MeCO}_{2} \mathrm{C}_{5} \mathrm{H}_{11}-\mathrm{n}+\mathrm{H}_{2} \mathrm{O}
$$

The temperature range of the study was $373.15-393.15 \mathrm{~K}$; it was chosen considering the conditions of the n-pentyl

- COSMO-RS (Conductor like Screening Model for Real Solvents) is a model to calculate and predict thermodynamic characteristics using quantum chemical methods; PC-SAFT (Perturbed-Chain Statistical Associating Fluid Theory) is one of modern state equations, which is used to compute thermodynamic characteristics. 
acetate synthesis. In addition to the quaternary system, the vapour-liquid equilibria were explored for binary subsystems: acetic acid-n-pentanol at $333.15 \mathrm{~K}$ and acetic acid-n-pentyl acetate in the temperature range of $353.15-393.15 \mathrm{~K}$. The data on the binary systems were used to estimate the binary interaction parameters in the NRTL model, which was also applied to calculations of the system characteristics.

\section{III.1.j. Acetic acid-n-hexanol-n-hexyl acetate-water}

A large body of data on the phase equilibria (vapour-liquid and liquid-liquid) in this system is presented in the paper of Schmitt and Hasse. ${ }^{58}$ The data include the equilibria in binary and ternary subsystems over wide temperature ranges $(280-440 \mathrm{~K})$ and pressures $(30-90 \mathrm{kPa})$.

$$
\mathrm{MeCO}_{2} \mathrm{H}+\mathrm{n}-\mathrm{C}_{6} \mathrm{H}_{13} \mathrm{OH} \rightleftharpoons \mathrm{MeCO}_{2} \mathrm{C}_{6} \mathrm{H}_{13}-\mathrm{n}+\mathrm{H}_{2} \mathrm{O}
$$

The tables of data contained in this paper include parameters of the phase equilibria for both isobaric and isothermal conditions. It was indicated that together with the available literature data, the results of this study form a complete high-quality database, which is necessary for modelling and simulation, as well as for design of the reactive distillation process. The calculations, correlations and simulations were performed using the NRTL model. The chemical equilibrium data were not reported.

III.1.k. Propionic acid-n-propanol-n-propyl propionate-water The phase equilibrium with simultaneous chemical equilibrium has not been studied in this system in recent years.

$$
\mathrm{EtCO}_{2} \mathrm{H}+\mathrm{Pr}^{\mathrm{n}} \mathrm{OH} \rightleftharpoons \mathrm{EtCO}_{2} \mathrm{Pr}^{\mathrm{n}}+\mathrm{H}_{2} \mathrm{O}
$$

The results of the study of Altman et al. ${ }^{59}$ on the phase equilibria should be noted. As in the case of many other studies of the phase equilibria in mixtures with a chemical reaction, the purpose of this work was to determine parameters necessary to design a reactive distillation process, viz., of the synthesis of n-propyl propionate in the presence of a catalyst (an acidic ion-exchange resin). The vapour-liquid equilibria were investigated at $101.3 \mathrm{kPa}$ for the binary systems such as n-propanol-propionic acid, n-propanol-n-propyl propionate, n-propyl propionate - propionic acid, water-n-propyl propionate, as well as the liquidliquid equilibrium in the n-propanol-n-propyl propionate-water ternary system at $101.3 \mathrm{kPa}$ and $288.15 \mathrm{~K}$. The choice of these systems was dictated by the fact that no data or insifficiently reliable data were reported for these systems in earlier works. It was noted that there is virtually no reaction between the acid and the alcohol without a catalyst: this fact is very important for direct determination of the vapour-liquid equilibrium in an alcohol-acid system. The authors noted that the data on six binary subsystems and one phase-separated ternary subsystem are sufficient to describe the phase behaviour of a quaternary system and to design a reactive distillation process. In accordance with the drawn conclusions, ${ }^{59}$ the parameters of the phase equilibrium in this system sufficient for practical purposes can be calculated (approximating the non-ideal vapour phase by the Hayden-O'Connell method) in terms of the UNIQUAC model; the binary interaction parameters for the UNIQUAC model were given.

\section{III.1.I. Propionic acid-isopentyl alcohol-isopentyl} propionate-water

The data on this system are not numerous, they are mainly related to the ester production.

$$
\mathrm{EtCO}_{2} \mathrm{H}+\operatorname{Pr}^{\mathrm{i}}\left(\mathrm{CH}_{2}\right)_{2} \mathrm{OH} \rightleftharpoons \mathrm{EtCO}_{2}\left(\mathrm{CH}_{2}\right)_{2} \mathrm{Pr}^{\mathrm{i}}+\mathrm{H}_{2} \mathrm{O}
$$

On the basis of the obtained experimental data on compositions corresponding to a chemical equilibrium, thermodynamic equilibrium constants were determined ${ }^{60}$ for several temperatures. The NRTL equation was applied to calculate the constants, the binary parameters of the NRTL model were taken from the literature. A weak dependence of the chemical equilibrium constants on the temperature was noted, although the accuracy of determination of the constant was not high: $K_{\mathrm{eq}}=63.42 \pm 14.68$.

\section{III.1.m. Oleic acid - methanol-methyl oleate - water}

The simultaneous chemical and phase (liquid-liquid) equilibrium in the system with the reaction of synthesis of methyl oleate was investigated at $346 \mathrm{~K} .{ }^{61}$

$$
\begin{aligned}
& \mathrm{Me}\left(\mathrm{CH}_{2}\right)_{7} \mathrm{CH}=\mathrm{CH}\left(\mathrm{CH}_{2}\right)_{7} \mathrm{CO}_{2} \mathrm{H}+\mathrm{MeOH} \rightleftharpoons \\
& \rightleftharpoons \mathrm{Me}\left(\mathrm{CH}_{2}\right)_{7} \mathrm{CH}=\mathrm{CH}\left(\mathrm{CH}_{2}\right)_{7} \mathrm{CO}_{2} \mathrm{Me}+\mathrm{H}_{2} \mathrm{O}
\end{aligned}
$$

The goal was to search for an alternative solution of the problem of phase separation in this system during the chemical reaction. The reaction between oleic acid and methanol was carried out in the presence of an ion exchange resin (in the $\mathrm{H}$ form) as a catalyst. The authors proposed an algorithm for calculation of the simultaneous phase and chemical equilibrium based on the use of the thermodynamic equilibrium constant and the UNIQUAC model.

\section{III.1.n. Lactic acid-methanol-methyl lactate-water}

Experimental data on the vapour-liquid equilibrium for 102 chemical equilibrium compositions in the system with the reaction of formation of methyl lactate under isobaric conditions $(101.33 \mathrm{kPa})$ were reported. ${ }^{62}$

$\mathrm{MeCH}(\mathrm{OH}) \mathrm{CO}_{2} \mathrm{H}+\mathrm{MeOH} \rightleftharpoons \mathrm{MeCH}(\mathrm{OH}) \mathrm{CO}_{2} \mathrm{Me}+\mathrm{H}_{2} \mathrm{O}$

Also, the activity and fugacity coefficients, as well as thermodynamic constants of the chemical equilibrium were given (the difference in the values of the latter can be attribited to some extent to the difference between the phase equilibrium temperatures, although it can also be due to the experimental error). The results of a study of the vapour-liquid equilibrium for the water-lactic acid binary system were also presented with indication of the content of the lactic acid dimer in the table of data; these experiments were conducted to estimate the parameters of the UNIQUAC model. The correlation of the data on the phase and chemical equilibria with the use of this model was reported. The phase equilibrium diagram for the chemical equilibrium state, which represented the surfaces of the liquid and vapour phases above the square of the transformed composition variables, was adduced; it was noted that no reactive azeotrope was observed.

III.1.o. Lactic acid-ethanol-ethyl lactate-water

Experimental data on the vapour-liquid equilibrium (115 chemical equilibrium compositions) for the system 
with the reaction of formation of ethyl lactate at $101.33 \mathrm{kPa}$ were obtained by Delgado et al. ${ }^{63}$

\section{$\mathrm{MeCH}(\mathrm{OH}) \mathrm{CO}_{2} \mathrm{H}+\mathrm{EtOH} \rightleftharpoons \mathrm{MeCH}(\mathrm{OH}) \mathrm{CO}_{2} \mathrm{Et}+\mathrm{H}_{2} \mathrm{O}$}

The experimental data were correlated using the UNIQUAC model, and activity coefficients were calculated. The dependence of the chemical equilibrium constant on temperature was analyzed. The diagram of the phase equilibrium for the chemical equilibrium states, which represents the surfaces of the liquid and vapour phases above the square of transformed composition variables, was presented; the existence of reactive azeotrope was not ascertained.

\section{III.2. Systems with other reactions}

This section is devoted to brief description of other reactive systems, for which there are data (experimental or computational), which make it possible to perform thermodynamic analysis or obtain a qualitative estimate of the simultaneous phase and chemical equilibrium.

III.2.a. Ethyl acetate - ethanol-n-propyl acetate-n-propyl alcohol This system corresponds to the transesterification reaction

$$
\mathrm{MeCO}_{2} \mathrm{Et}+\mathrm{Pr}^{\mathrm{n}} \mathrm{OH} \rightleftharpoons \mathrm{MeCO}_{2} \mathrm{Pr}^{\mathrm{n}}+\mathrm{EtOH}
$$

A vapour-liquid equilibrium and a chemical equilibrium in the ethyl acetate-ethanol-n-propyl acetate-n-propyl alcohol system was studied at 323.15 and $348.15 \mathrm{~K} ;{ }^{69}$ data about 116 chemical equilibrium compositions were obtained. The vapour-liquid equilibrium was studied at the same temperatures in all of six binary subsystems. These data were used to estimate the binary interaction parameters in the NRTL model. The calculated equilibrium parameters for the quaternary system agree well with the experimental data. In the course of determination of compositions corresponding to the chemical equilibrium, it was found that the transesterification does not occur in the absence of a catalyst both in the case of the ethanoln-propyl acetate system and in the case of the n-propanol-ethyl acetate. This fact facilitated the research of the phase equilibrium in both binary systems of the reactants. In the presence of a catalyst ( 0.02 mass $\%$ of potassium tertbutoxide), the chemical equilibrium is reached quite fast $(<30 \mathrm{~min})$. Three-dimensional phase diagrams in transformed composition variables were presented in the publication, they included the surfaces of the liquid and vapour phases for the chemical equilibrium state in the quaternary system. Azeotropic compositions were ascertained for three binary subsystems, viz., ethanol-ethyl acetate, ethanoln-propyl acetate, n-propyl alcohol-n-propyl acetate.

III.2.b. Methyl acetate-methanol-n-propyl acetate-n-propanol The transesterification reaction in this system was analyzed with the purpose of design of the reactive distillation process (isolation of methanol and n-propyl acetate). ${ }^{70}$

$$
\mathrm{MeCO}_{2} \mathrm{Me}+\operatorname{Pr}^{\mathrm{n}} \mathrm{OH} \rightleftharpoons \mathrm{MeCO}_{2} \mathrm{Pr}^{\mathrm{n}}+\mathrm{MeOH}
$$

Thermodynamic data on this system are quite limited. It was noted that in analogous earlier studies, the activity coefficients for transesterification of methyl acetate with nbutanol or n-hexanol were determined using the NRTL, UNIQUAC or UNIFAC models, while the reactive distil- lation was modelled in terms of UNIQUAC. Therefore, the latter model was chosen by the authors to estimate the activity coefficients and other thermodynamic characteristics of this system.

III.2.c. Methyl acetate-methanol-isopropyl acetate-isopropanol The methyl acetate-methanol-isopropyl acetate-isopropanol system with transesterification reaction was studied by Xiao et al. ${ }^{71}$

$\mathrm{MeCO}_{2} \mathrm{Me}+\mathrm{Pr}^{\mathrm{i}} \mathrm{OH} \rightleftharpoons \mathrm{MeCO}_{2} \mathrm{Pr}^{\mathrm{i}}+\mathrm{MeOH}$

Data on the vapour-liquid equilibrium were obtained under isobaric conditions at $101.3 \mathrm{kPa}$ for the quaternary system and one of the binary systems (methyl acetate-isopropyl acetate). For other binary systems, the authors used available literature data. The data were correlated using the Wilson model and the NRTL and UNIQUAC models. The results of the calculations of the equilibrium parameters for the quaternary system indicated that the best correspondence to the experimental data was achieved with the use of the NRTL model. It is necessary to note that experimental data obtained in this study were limited to determination of 16 compositions for the quaternary system and 10 compositions for the binary system. In addition, since the paper gives no information on the chemical equilibrium, the presented data on the vapour-liquid equilibrium in the quaternary system do not correspond, apparently, to a simultaneous chemical equilibrium.

\section{General discussion of the data on the phase and chemical equilibria in multicomponent systems with chemical reactions}

In this Section, some general conclusions concerning multicomponent heterogeneous fluid systems with chemical reactions are made based on the thermodynamic regularities discussed in Section II and the results of the analysis of particular systems given in Section III. First of all, it should be noted that the current database of the experimentally obtained results is rather limited. The present review does not claim to give exhaustive information on the phase equilibria in chemically reacting systems; however, it covers quite a number of available publications. The cited studies were mainly devoted to quite simple cases, in particular, they rarely considered the possibility of parallel reactions or processes in the gas phase, although thermodynamic analysis always took into account dimerization of acetic acid in the gas phase.

Experimental investigation of the phase and chemical equilibria in the systems with the esterification or transesterification reaction have a practical importance for chemical engineering, on the one hand, and are of fundamental scientific interest, on the other hand. Indeed, these systems are good subjects for a physicochemical analysis because of applicability of conventional methods for studying phase and chemical equilibria. Of course, a wide range of chemically reacting heterogeneous systems are significant for chemical industry; however, due to complexity of experimental studies, the experimental data obtained are limited and incomplete. For instance, data on multicomponent systems, in which not all of the substances react, are presented in some publications (not cited in this review). As a rule, such investigations deal with the ways of arrangement of reactive distillation processes and do not give 
sufficiently detailed information on the phase equilibria and thermodynamic characteristics. The study by Chen et al. ${ }^{72}$ represents a recent research of this type considering direct hydration of cyclohexene for the production of cyclohexanol. Since the number of studies of this type of ternary systems is scanty, as it was noticed in the introduction to this review, data on the combined phase and chemical equilibrium in the cyclohexene-water-cyclohexanol system might have been of interest. However, due to the engineering peculiarity of this process, this study actually analyzes the system of four compounds, including cyclohexane as an impurity that necessarily accompanies the process. In any case, as regards the vapour-liquid and vapour-liquid-liquid equilibria, the authors restrict themselves to reporting only the parameters of the NRTL model.

Note also that due to the obvious experimental complexity of complete and detailed analysis of the phase and chemical equilibria in the systems containing five or more compounds (because of the need for very large amounts of data) or in the systems with several chemical reactions, it is reasonable to use computational methods for thermodynamic modelling to solve current engineering problems. The parameters of suitable models can be determined or refined on the basis of the experimental data obtained for simpler subsystems. Usually, the studies of this sort are aimed at solving the problems of design of reactive distillation, extraction and other combined processes. ${ }^{73-75}$

At the same time, direct experimental assessment of the phase and chemical equilibrium parameters remains a priority task, in particular, as applied to chemical engineering. Particularly, despite the modest number of publications devoted to combined phase and chemical equilibrium in systems with the transesterification reaction, one may expect a sharp increase in the number of these publications in the future because of importance of this process, particularly, for the production of biofuel. ${ }^{76}$

One of the problems faced by experimental studies of the phase equilibria as a chemical reaction proceeds consists in the change in the composition of the solution under study due to the reaction. In this connection, attention is drawn to the difference of views of different authors on the possibility of direct measurement of parameters of the phase equilibrium in reacting mixtures. As a rule, it is assumed in the studies of chemically non-equilibrium systems of reactants and products of esterification reaction that the reaction can be neglected in the absence of a catalyst, i.e., the composition change due to the reaction is insignificant througout the experiment. However, it is not always true for acidalcohol binary systems as certain amounts of the reaction products can be detected in some cases in the study of a vapour-liquid equilibrium even in the absence of a catalyst. Therefore, the parameters of the vapour-liquid equilibrium in the binary systems formed by formic acid and isopropanol, ethanol and methanol were obtained taking into account the changes in the composition along the stoichiometric lines during the reaction. ${ }^{37}$ A detailed procedure of determination of the parameters using the Wilson model was described in the paper cited. ${ }^{37}$ Simultaneously, the authors also obtained data on the quaternary reacting system. Note that in this case, fast reactions with formic acid were considered. In a study of the mixtures of acetic acid with methanol and ethanol, ${ }^{65}$ the possibility of the reactions between the binary systems components was not indicated. However, a slow reaction between acetic acid and methanol was noted earlier, ${ }^{66}$ and to avoid a change in the solution composition, the duration of the experimental determination of the equilibrium with vapour was reduced. ${ }^{66}$ As a result, the authors presented only a part of the experimental data obtained since some results were still rejected because reaction products were detected during the analysis of the phase equilibrium. It is necessary to note that the vapour-liquid equilibrium was determined in these studies ${ }^{65,66}$ under different conditions. As for the acetic acid-ethanol system, no possibility of the reaction between the acid and ethanol (i.e., between participants of the esterification reaction) was indicated in a study 68 performed in 2014 where the vapour pressure was determined at $298.15 \mathrm{~K}$ in the absence of a catalyst. In the studies devoted to the analysis of the vapour-liquid equilibrium in the binary systems formed by reactants of the esterification reaction represented by fatty acids and alcohols the possibility of formation of the reaction products is usually neglected starting with butyric acid. ${ }^{77}$

Section II of this review presents a number of specific features of the state diagrams of reactive systems brought about by the chemical reactions proceeding in the systems. At the same time, available experimental data are only in some cases adequate for performing thermodynamic analysis of these specific features because of incompleteness of these data. Recall that representation of the composition of a four-component system alone requires three-dimensional concentration space (the composition tetrahedron), whereas the representation of a phase equilibrium or some other thermodynamic quantity requires additional space coordinates. The use of the transformed composition variables $(\alpha$-variables) enables one to construct three-dimensional diagrams for the dependences of thermodynamic characteristics on the composition for the chemical equilibrium states. In turn, isolines of the thermodynamic characteristics can be shown on these thermodynamic surfaces. A certain inconvenience from imaging of the three-dimensional diagrams in a plane can be compensated by construction of projections of the isolines of thermodynamic characteristics onto the coordinate plane of $\alpha$-variables. Unfortunately, the advantages of the transformed composition variables were utilized only in a minor part of publications considered here, and, as it was noted above, this is due to shortage of systematic data on the thermodynamic characteristics of systems under chemical equilibrium. Analogous representations of properties are possible not only for chemical equilibrium surfaces, but also for other isoaffine surfaces. Note that the affinity (chemical affinity) is an important thermodynamic parameter, which characterises the deviation of a reaction mixture from the equilibrium state; nevertheless, this quantity is rarely considered in analysis of characteristics of a particular system. In our opinion, it reduces the capabilities of the thermodynamic analysis of systems with chemical reactions.

The change in the thermodynamic characteristics along reaction (stoichiometric) lines is also considered quite rarely in the studies of reacting systems, although the advantage of such consideration is exemplified by a study of Tischmeyer and Arlt $^{37}$ where the pressure change during a chemical reaction, i.e., along such lines, was investigated. The data on changes of thermodynamic quantities during non-equilibrium chemical reaction represent important characteristics, which are essential for design of chemical engineering processes (reactive distillation, for instance), but the deficiency in such information in modern basic researches of reactive mass-transfer processes is obvious. 
In some of the studies considered in the present review, there are data concerning variations in pressure on the chemical equilibrium surfaces, including the pressure extremums on these surfaces (for instance, for the equilibrium states of the system with the reaction of n-propyl acetate synthesis ${ }^{47}$ ). The presence or absence of a reactive azeotrope in particular systems was discussed in several studies. ${ }^{42,62,63}$ The patterns of curves of combined reactive mass-transfer processes on the chemical equilibrium surfaces was also presented in some publications. ${ }^{28,42,43,47}$

The problem of relative arrangement of chemical and phase equilibrium surfaces in the concentration space, which was mentioned in Section II, has a clear practical significance when phase-separated reaction mixtures are considered. A typical general view of the chemical equilibrium and binodal surfaces and their locations in the composition tetrahedron for the systems with the esterification-ester hydrolysis reaction are presented in Fig. 4.

Obviously, the data on phase separation in the reaction mixtures and the concentration regions of limited miscibility of compounds have not only fundamental interest, but are also important for practical applications, including the design of synthetic processes. The intersection of the binodal and chemical equilibrium surfaces in the concentration tetrahedron or, in other words, the reactive systems in which there is equilibrium in both homogeneous and heterogeneous regions of compositions are of special interest. In particular, this phenomenon is expected of the systems with the esterification reaction since the limited miscibility of the reaction products, viz., water and ester, determines the existence of the phase separation. At the same time, only homogeneous regions of solution compositions are considered in most of studies of these systems. The data on the combined phase and chemical equilibrium in the heterogeneous composition regions were reported only in a few experimental works (for example, see Refs. 48, 49, 54). The diagram depicted in Fig. 5 (the concentration tetrahedron in Fig. $5 a$ and the square of transformed composition variables in Fig. $5 b$ ) schematically shows the region of the intersection of a chemical equilibrium surface and a binodal (a shaded region inside the $C_{1}-C_{2}$ closed curve). For the sake of clarity, this part of Fig. 5 is provided separately on an enlarged scale.

The phase separation region of a liquid mixture being under chemical equilibrium gives rise to existence of critical liquid-liquid states also being under chemical equilibrium. The critical curve of the liquid-liquid equilibrium is also shown in Fig. 5; clearly, only two critical points $C_{1}$ and $C_{2}$

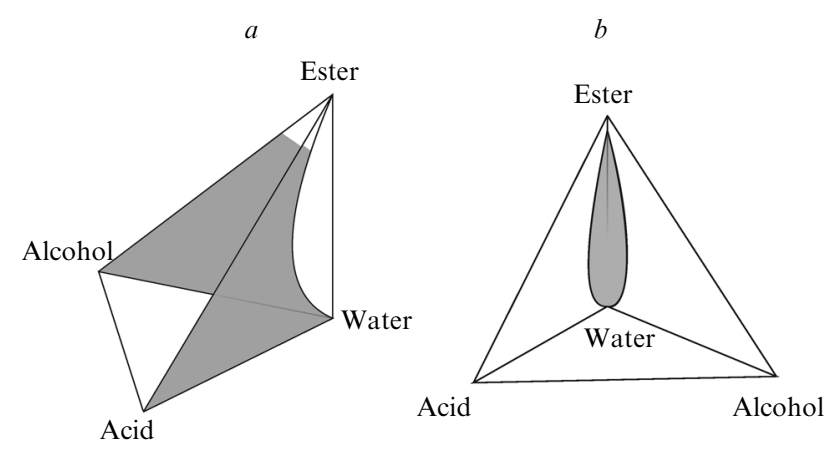

Figure 4. General view of the chemical equilibrium surface $(a)$ and the binodal surface $(b)$ in a system with the esterification reaction.
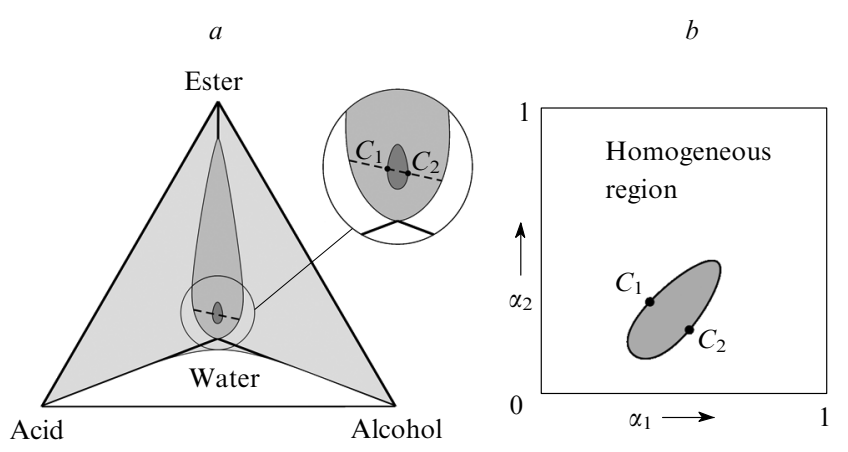

Figure 5. Region of intersection of the chemical equilibrium surface and the binodal surface in a system with the esterification reaction (see text) in the concentration tetrahedron $(a)$ and in the square of $\alpha$-variables $(b) .^{10}$

$C_{1}, C_{2}$ are the critical points of the liquid-liquid equilibrium, which also correspond to chemical equilibrium compositions; the dashed line is the critical curve in the concentration tetrahedron.

at the border of intersection of the surfaces under consideration correspond to chemical equilibrium states. The critical curves of the liquid-liquid equilibrium represent additional singularities, which are important to characterize the structure of diagrams of multicomponent systems. The

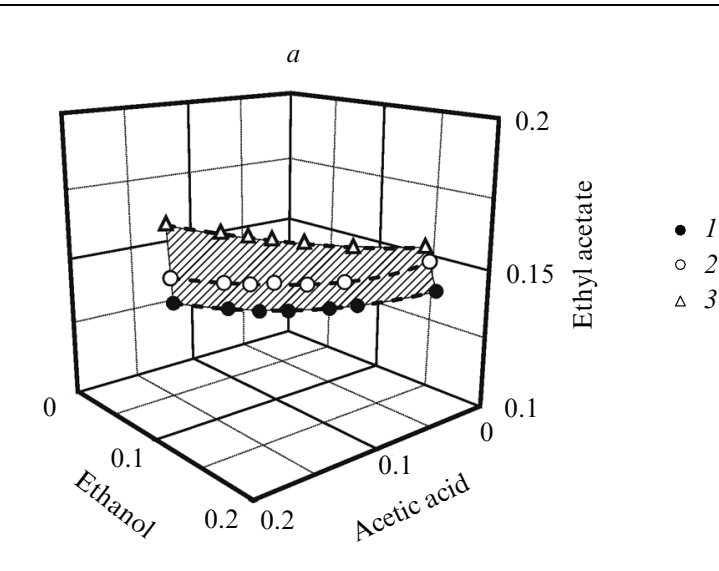

$b$

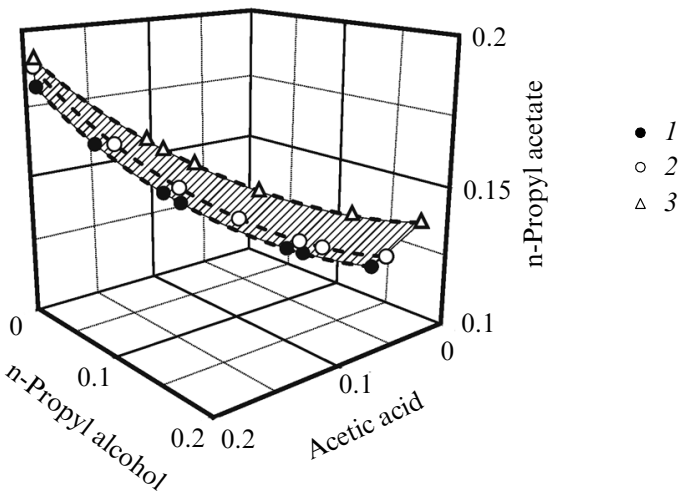

Figure 6. Critical surfaces in the acetic acid-ethanol-ethyl acetate-water systems (according to the data from Ref. 78) (a) and acetic acid-n-propyl alcohol-n-propyl acetate-water system (according to the data from Refs. 48 and 79) (b).

Critical curves at 293.15 (1), 303.15 (2), $313.15 \mathrm{~K}$ (3). The compositions are in mole fractions. 


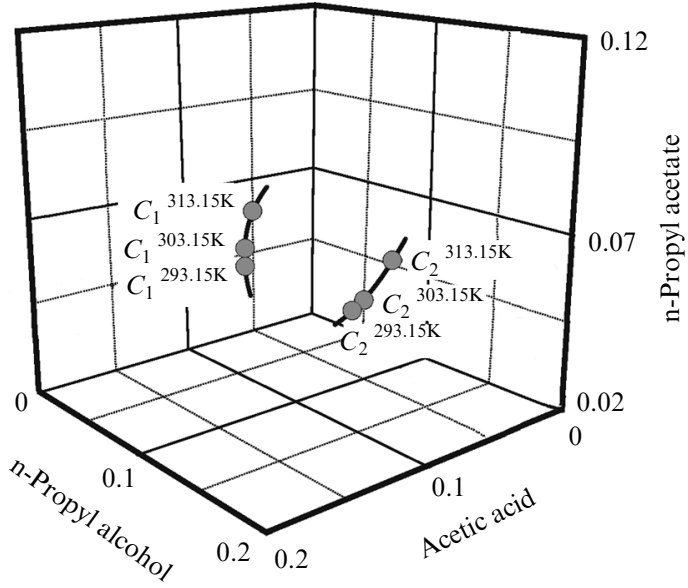

Figure 7. Critical curves which correspond to chemical equilibrium compositions under polythermal conditions in the acetic acid-n-propyl alcohol-n-propyl acetate-water system. ${ }^{29,48,79}$ $C_{1}, C_{2}$ are the critical points in the corresponding curves with indication of the temperatures.

whole set of critical curves, which belong to a polythermal critical surface, can be constructed on the basis of data obtained at several temperatures. Critical surfaces of this type for two quaternary systems are presented in Fig. 6.

Despite the similar appearance of polythermal critical surfaces, the critical curves for the acetic acid-n-propyl alcohol-n-propyl acetate - water system intersect the chemical equilibrium region at all temperatures. Thus, each curve has two points corresponding to a chemical equilibrium state. Therefore, two chemical equilibrium polythermal critical curves can be constructed for this system (Fig. 7).

Since the studies of phase equilibria in chemically reactive media are associated with practically important synthetic problems, appreciable attention is paid in modern studies to the kinetics of non-equilibrium chemical reactions. At the same time, the main attention is usually focused on homogeneous systems even in the studies devoted to substantiation and design of reactive distillation processes, where kinetic regularities are important for assessment of not only equilibrium, but also stationary parameters. The problems of kinetics of chemical processes in heterogeneous liquid-phase systems while maintaining (restoring) a phase equilibrium deserve separate consideration outside the scope of this review.

\section{Conclusions}

On the basis of the above analysis of theoretical and experimental aspects of the problem of phase and chemical equilibria in multicomponent systems with chemical reactions in the liquid phases, one can make some conclusions concerning further development of this research area. First, despite the substantial amount of data gained so far, the number of experimentally obtained results is not too large yet, and the extension of this database is highly desirable. Second, the development of the theoretical thermodynamic analysis is restrained by incompleteness of many performed studies since they were aimed at solution of some practical problems but not fundamental physicochemical ones. Third, the discussed thermodynamic regularities and the analysis of the simultaneous phase and chemical equilibrium in particular systems shows the complexity of the behaviour of multicomponent heterogeneous systems and their state diagrams if chemical and phase processes occur simultaneously; it is necessary to take into account not only the surfaces of phase and chemical equilibria, but also additional elements such as reaction (stoichiometric) lines and the surfaces of constant chemical affinity, i.e., in this particular case, of the chemical equilibrium. One could also expect the development of a complex thermodynamickinetic approach based on the experimental data on the rates of phase transitions and simultaneous chemical reactions, in particular, for the processes in phase-separated liquid systems. Fundamental research along this line has obvious prospects for both the search for new physicochemical regularities and practical applications in the design of reactive mass-transfer processes in chemical engineering.

The review was wtitten with financial support of the research Grant 12.38.257.2014 provided by the Saint Petersburg State University.

\section{References}

1. Yu A Pisarenko, K A Kardona, L A Serafimov Reaktsionno-rektifikatsionnye Protsessy: Dostizheniya v Oblasti Issledovaniya i Prakticheskogo Ispol'zovaniya (Reaction-Rectification Processes: Advances in Research and Practical Use) (Moscow: Luch, 2001)

2. Distillation: Equipment and Processes (Eds A Górak, Ž Olujić) (1st Ed.) (Academic Press, 2014)

3. Yu A Pisarenko, L A Serafimov, N N Kulov Theor. Found. Chem. Eng. 43591 (2009) [Teor. Osnovy Khim. Tekhnol. 43491 (2009)]

4. K Sundmacher, A Kienle Reactive Distillation. Status and Future Directions (Weinheim: Wiley, 2003)

5. Distillation: Fundamentals and Principles (Eds A Górak, E Sorensen) (1st Ed.) (Academic Press, 2014)

6. A S Shuvalov, M A Malysheva, Yu A Pisarenko Theor. Found. Chem. Eng. 37464 (2003) [Teor. Osnovy Khim. Tekhnol. 37497 (2003)]

7. N M Eleftheriades, H von Blottnitz Environ. Prog. Sustain. Energy 32373 (2013)

8. A Heintz, S P Verevkin Fluid Phase Equilib. 17985 (2001)

9. A M Toikka, M A Toikka, Yu A Pisarenko, L A Serafimov Theor. Found. Chem. Eng. 43129 (2009) [Teor. Osnovy Khim. Tekhnol. 43141 (2009)]

10. A M Toikka, M A Toikka, M A Trofimova Russ. Chem. Bull., Int. Ed. 61741 (2012) [Izv. Akad. Nauk, Ser. Khim. 737 (2012)]

11. I Prigogine, R Defay Chemical Thermodynamics (New York: Wiley, 1962)

12. A V Storonkin Termodinamika Geterogennykh Sistem (Thermodynamics of Heterogeneous Systems) Pts 1, 2 (Leningrad: Leningrad State University, 1967)

13. V T Zharov Zh. Fiz. Khim. 441967 (1970) ${ }^{\mathrm{a}}$

14. S Yu Shalunova, Yu A Pisarenko, A S Shuvalov, L A Serafimov Theor. Found. Chem. Eng. 3831 (2004) [Teor. Osnovy Khim. Tekhnol. 3833 (2004)]

15. V T Zharov, O K Pervukhin J. Phys. Chem. USSR 461965 (1972) [Zh. Fiz. Khim. 461970 (1972)]

16. A M Toikka, J D Jenkins Chem. Eng. J. 891 (2002)

17. A V Penkova, G A Polotskaya, A M Toikka Chem. Eng. Sci. 101586 (2013)

18. A M Toikka, in Distillation Absorption 2010 (Conference Proceedings) (Eds A B Haan, H Kooijman, A Górak) (Eindhoven, Netherlands, 2010) p. 331 
19. S Bernatová, K Aim, I Wichterle Fluid Phase Equilib. 24796 (2006)

20. D Barbosa, M F Doherty Proc. R. Soc. London, Ser. A 413459 (1987)

21. V T Zharov, O K Pervukhin Vestn. Leningr. Univ., Ser. Fiz., Khim. (10) 102 (1977)

22. A M Toikka Vestn. St Petersburg. Univ. (4) 63 (2004)

23. B I Gorovits, A M Toikka Dokl. Phys. Chem. 405244 (2005) [Dokl. Akad. Nauk 405364 (2005)]

24. B I Gorovits, A M Toikka, Yu A Pisarenko, L A Serafimov Theor. Found. Chem. Eng. 40239 (2006) [Teor. Osnovy Khim. Tekhnol. 40258 (2006)]

25. A S Shuvalov, Yu A Pisarenko Theor. Found. Chem. Eng. 35 133 (2001) [Teor. Osnovy Khim. Tekhnol. 35142 (2001)]

26. S Ung, M F Doherty Chem. Eng. Sci. 503201 (1995)

27. Z Qi, A Kolah, K Sundmacher Chem. Eng. Sci. 57163 (2002)

28. A C Dimian, F Omota, A Bliek Chem. Eng. Process. Process Intensif. 43411 (2004)

29. M Toikka, A Toikka Pure Appl. Chem. 85277 (2013)

30. A M Toikka, A A Samarov, in The 10th International Conference on Distillation and Absorption 2014 (Book of Full Papers) (Frankfurt am Main: DECHEMA, 2014) p. 46

31. Yu A Pisarenko Russ. J. Phys. Chem. 821 (2008) [Zh. Fiz. Khim. 825 (2008)]

32. L A Serafimov, T V Chelyuskina Theor. Found. Chem. Eng. 48 254 (2014) [Teor. Osnovy Khim. Tekhnol. 48274 (2014)]

33. L A Serafimov Theor. Found. Chem. Eng. 43268 (2009) [Teor. Osnovy Khim. Tekhnol. 43284 (2009)]

34. D V Medvedev, L A Serafimov Theor. Found. Chem. Eng. 45 420 (2011) [Teor. Osnovy Khim. Tekhnol. 45445 (2011)]

35. L A Serafimov, A V Frolkova, D V Medvedev, G A Semin Theor. Found. Chem. Eng. 46120 (2012) [Teor. Osnovy Khim. Tekhnol. 46154 (2012)]

36. B Indu, W R Ernst, L T Gelbaum Ind. Eng. Chem. Res. 32981 (1993)

37. M Tischmeyer, W Arlt Chem. Eng. Process. Process Intensif. 43 357 (2004)

38. R F Schultz J. Am. Chem. Soc. 611443 (1939)

39. Y-C Zhang, T Qiu J. Chem. Eng. Chin. Univ. 27380 (2013)

40. C Zuo, L Pan, S Cao, C Li, S Zhang Ind. Eng. Chem. Res. 53 $10540(2014)$

41. S Bernatová, K Aim, I Wichterle J. Chem. Eng. Data 5220 (2007)

42. G Modla Comput. Chem. Eng. 352401 (2011)

43. H-d Zheng, H Tian, W-h Zou, Z-x Huang, X-d Wang, T Qiu, S-y Zhao, Y-x Wu J. Cent. South Univ. 2050 (2013)

44. A M Toikka, M A Trofimova, M A Toikka Russ. Chem. Bull., Int. Ed. 61662 (2012) [Izv. Akad. Nauk, Ser. Khim. 659 (2012)]

45. M Trofimova, M Toikka, A Toikka Fluid Phase Equilib. 31346 (2012)

46. A Wyczesany Ind. Eng. Chem. Res. 465437 (2007)

47. A M Toikka, M A Toikka Fluid Phase Equilib. 25093 (2006)

48. M A Toikka, B I Gorovits, A M Toikka Russ. J. Appl. Chem. 81223 (2008) [Zh. Prikl. Khim. 81234 (2008)]

49. A Toikka, M Toikka Pure Appl. Chem. 811591 (2009)

50. M A Toikka, N S Tsvetov, A M Toikka Theor. Found. Chem. Eng. 45429 (2011) [Teor. Osnovy Khim. Tekhnol. 45454 (2011)]

51. M A Toikka, N S Tsvetov, A M Toikka Theor. Found. Chem. Eng. 47554 (2013) [Teor. Osnovy Khim. Tekhnol. 47534 (2013)]

52. G Venimadhavan, G Buzad, M F Doherty, M F Malone AIChE J. 401814 (1994)

53. F R Bevia, D P Rico, V G Yagües, P V Galvañ Fluid Phase Equilib. 18171 (1984)

54. S Grob, H Hasse J. Chem. Eng. Data 5092 (2005)

55. V I Zhuchkov, Yu A Pisarenko, A K Frolkova Theor. Found. Chem. Eng. 43482 (2009) [Khim. Tekhnol. 9204 (2008)]

56. E Lladosa, J B Montón, M C Burguet, R Muñoz J. Chem. Eng. Data $\mathbf{5 3} 108$ (2008)
57. M-J Lee, S-L Chen, C-H Kang, H-m Lin Ind. Eng. Chem. Res. 394383 (2000)

58. M Schmitt, H Hasse J. Chem. Eng. Data 501677 (2005)

59. E Altman, G D Stefanidis, T van Gerven, A I Stankiewicz J. Chem. Eng. Data 562322 (2011)

60. F Leyva, A Orjuela, D J Miller, I Gil, J Vargas, G Rodríguez Ind. Eng. Chem. Res. 5218153 (2013)

61. F Chen, H Sun, Y Naka, J Kawasaki J. Chem. Eng. Jpn. 34 $1479(2001)$

62. M T Sanz, S Beltrán, B Calvo, J L Cabezas J. Chem. Eng. Data 481446 (2003)

63. P Delgado, M T Sanz, S Beltrán Fluid Phase Equilib. 25517 (2007)

64. Yu A Pisarenko, M I Balashov Zh. Fiz. Khim. 531656 $(1979)^{\mathrm{a}}$

65. I R Navarro-Espinosa, C A Cardona, J A Ldpez Fluid Phase Equilib. 287141 (2010)

66. S Horstmann, T Pöpken, J Gmehling Fluid Phase Equilib. 180 $221(2001)$

67. S Hu, B-j Zhang, X-q Hou, D-1 Li, Q-1 Chen Chem. Eng. Process. Process Intensif. 501252 (2011)

68. S Brandt, S Horstmann, S Steinigeweg, J Gmehling Fluid Phase Equilib. 37648 (2014)

69. J Pavlíček, G Bogdanić, I Wichterle Fluid Phase Equilib. 328 61 (2012)

70. L Shen, L Wang, H Wan, G Guan Ind. Eng. Chem. Res. 53 $3827(2014)$

71. L Xiao, Q-1 Wang, H-x Wang, T Qiu Fluid Phase Equilib. 344 79 (2013)

72. B-C Chen, B-Y Yu, Y-L Lin, H-P Huang, I-L Chien Ind. Eng. Chem. Res. $\mathbf{5 3} 7079$ (2014)

73. A K Frolkova, O N Krupinova, S A Prokhorova Theor. Found. Chem. Eng. 47489 (2013) [Khim. Tekhnol. 13121 (2012)]

74. D Kang, K Lee, J W Lee Ind. Eng. Chem. Res. 5312387 (2014)

75. N N Kulov, N P Slaikovskaya, V A Lotkhov Theor. Found. Chem. Eng. 46113 (2012) [Teor. Osnovy Khim. Tekhnol. 46147 (2012)]

76. E F Aransiola, T V Ojumu, O O Oyekola, T F Madzimbamuto, D I O Ikhu-Omoregbe Biomass Bioenergy 61276 (2014)

77. S A Iwarere, J D Raal, P Naidoo, D Ramjugernath Fluid Phase Equilib. 38018 (2014)

78. M Toikka, A Samarov, M Trofimova, A Golikova, N Tsvetov, A Toikka Fluid Phase Equilib. 37372 (2014)

79. M Toikka, A Samarov, A Toikka Fluid Phase Equilib. 37566 (2014)

a - J. Phys. Chem. USSR (Engl. Transl.) 